\title{
Multiplex polymerase chain reaction to identify and determine the toxigenicity of Corynebacterium spp with zoonotic potential and an overview of human and animal infections
}

\author{
Luciene de Fátima Costa Torres ${ }^{1}$, Dayana Ribeiro ${ }^{2}$, Raphael Hirata Jr'1, \\ Luis Gustavo Carvalho Pacheco ${ }^{3}$, Monica Cristina Souza ${ }^{1}$, Louisy Sanches dos Santos ${ }^{1}$, \\ Cíntia Silva dos Santos ${ }^{1}$, Mohammad Salah ${ }^{4}$, Mateus Matiuzzi da Costa ${ }^{5}$, Marcio Garcia Ribeiro' \\ Salah A Selim", Vasco Ariston de Carvalho Azevedo², Ana Luiza Mattos-Guaraldi'/+
}

\footnotetext{
'Laboratório de Difteria e Corinebactérias de Importância Clínica, Faculdade de Ciências Médicas, Universidade do Estado do Rio de Janeiro, Rio de Janeiro, RJ, Brasil ²Departamento de Biologia, Instituto de Ciências Biológicas, Universidade Federal de Minas Gerais, Belo Horizonte, MG, Brasil ${ }^{3}$ Departamento de Biointeração, Instituto de Ciências da Saúde, Universidade Federal da Bahia, Salvador, BA, Brasil

${ }^{4}$ Faculdade de Medicina Veterinária, Universidade do Cairo, Giza, Egito ${ }^{5}$ Fundação Universidade Federal do Vale do São Francisco, Petrolina, PE, Brasil ${ }^{6}$ Departamento de Higiene Veterinária e Saúde Pública, Escola de Medicina Veterinária e Ciência Animal, Universidade Estadual Paulista, Botucatu, SP, Brasil
}

Corynebacterium diphtheriae, Corynebacterium ulcerans and Corynebacterium pseudotuberculosis constitute a group of potentially toxigenic microorganisms that are related to different infectious processes in animal and human hosts. Currently, there is a lack of information on the prevalence of disease caused by these pathogens, which is partially due to a reduction in the frequency of routine laboratory testing. In this study, a multiplex polymerase chain reaction ( $m P C R$ ) assay that can simultaneously identify and determine the toxigenicity of these corynebacterial species with zoonotic potential was developed. This assay uses five primer pairs targeting the following genes: rpoB (Corynebacterium spp), 16S rRNA (C. ulcerans and C. pseudotuberculosis), pld (C. pseudotuberculosis), dtxR (C. diphtheriae) and tox [diphtheria toxin (DT)]. In addition to describing this assay, we review the literature regarding the diseases caused by these pathogens. Of the 213 coryneform strains tested, the mPCR results for all toxigenic and non-toxigenic strains of $\mathrm{C}$. diphtheriae, C. ulcerans and C. pseudotuberculosis were in 100\% agreement with the results of standard biochemical tests and PCR-DT. As an alternative to conventional methods, due to its advantages of specificity and speed, the mPCR assay used in this study may successfully be applied for the diagnosis of human and/or animal diseases caused by potentially toxigenic corynebacterial species.

Key words: mPCR - C. diphtheriae - C. ulcerans - C. pseudotuberculosis - diphtheria toxin

Corynebacterium species constitute a group of microorganisms related to different infectious processes involving both animal and human hosts (Seto et al. 2008). The gene for diphtheria toxin (DT) is present in bacteriophages capable of infecting Corynebacterium diphtheriae, Corynebacterium ulcerans and Corynebacterium pseudotuberculosis (Wong \& Groman 1984, Pappenheimer 1993).

C. diphtheriae is the primary causative agent of diphtheria, a toxaemic disease whose prevention depends on the implementation of effective immunisation programs using toxoid molecules (Hadfield et al. 2000). In many developing countries, diphtheria continues to have a high case fatality rate due to the inadequate nationwide coverage of immunisation programs (Mattos-Guaraldi et al.

Financial support: CNPq, CAPES, FAPERJ, SR-2/UERJ, PRONEX $\mathrm{L}$ de FCT and DR contributed equally to this work.

+ Corresponding author: guaraldi@uerj.br

Received 29 April 2012

Accepted 14 September 2012
2003, Saikya et al. 2010). The potential for $C$. diphtheriae to spread epidemically and the fact that some strains have recently been isolated from domestic animals indicate that there is a risk for the zoonotic circulation of the tox gene although the spread of toxigenic $C$. diphtheriae among humans is considered as under control (Hall et al. 2010, Leggett et al. 2010).

Recently, cases of diphtheria (Aaron et al. 2006), mostly in European and North American countries (CDC 2000, von Hunolstein et al. 2003, DeWinter et al. 2005, Bonmarin et al. 2009, Wagner et al. 2011), caused by $C$. ulcerans have been reported and some infections were reported to be related to animal transmission (Hogg et al. 2009, Wagner et al. 2011). However, there have been few reported cases of zoonotic diphtheria due to C. $u l$ cerans in developing countries (Dias et al. 2011), especially in countries with large livestock populations and/ or deficient child immunisation programs. Other types of human infections caused by C. ulcerans have been described (Taylor et al. 2002, Mattos-Guaraldi et al. 2008). Moreover, infection by toxigenic $C$. ulcerans has also reported in animals, including cattle, pigs and small pets, such as cats and dogs (De Zoysa et al. 2005, Lartigue et al. 2005, Katsukawa et al. 2009, 2012, Schuhegger et al. 2009, Sykes et al. 2010). In Brazil, a survey performed in 
an animal shelter for abandoned dogs found an asymptomatic dog colonised by a non-toxigenic $C$. ulcerans strain (Dias et al. 2010).

C. pseudotuberculosis is the aetiological agent of caseous lymphadenitis (CLA) in small ruminants, such as sheep and goats. This infection sometimes presents as pneumonia, hepatitis, pericarditis, mastitis, arthritis or subcutaneous abscesses. This pathogen is also associated with lymphadenitis in horses and with ulcerative lymphangitis in cattle (Foley et al. 2004, Perkins et al. 2004, Baird \& Fontaine 2007, Sharpe et al. 2010). Two biotypes of $C$. pseudotuberculosis, which are differentiated based on nitrate-reducing ability, have been reported: nitrate-negative strains are referred to as serotype I (biotype ovis) and nitrate-positive strains are classified as serotype II (biotype equi). Isolates from sheep and goats are usually nitrate negative, whereas strains from horses are typically nitrate positive; isolates from cattle are variable (Tejedor-Junco et al. 2008, Wagner et al. 2011). Although C. pseudotuberculosis is distributed worldwide, it has the most serious economic impact in Oceania, Africa and South America, including Argentina and Brazil (Estevao et al. 2007, Komala et al. 2008, Stefanska et al. 2008, Tarello \& Theneyan 2008, Seyffert et al. 2010). Once established, CLA is difficult to eradicate because drug therapy is not effective and the clinical detection of infected animals is of limited efficiency (Dorella et al. 2006). Early microbiological diagnosis and long-term antimicrobial treatment are important for a successful outcome in horses with C. pseudotuberculosis infection (Pratt et al. 2005). Similar to diphtheria in humans (Kombarova et al. 2001, Saikya et al. 2010), C. pseudotuberculosis can cause clonally expanding epidemics in animals. The increase in the number of infections could be the result of a reporting bias, environmental factors that facilitate infection or host factors, such as greater herd susceptibility (Foley et al. 2004).

C. pseudotuberculosis can be spread among animals by fly vectors, such as Musca domestica and Hippobosca equina, as previously observed in the United States of America (USA), Israel and Egypt. This pathogen can be found in up to $20 \%$ of flies in the vicinity of diseased animals (Yeruham et al. 1996, Braverman et al. 1999, Selim 2001, Spier et al. 2004). Oedematous skin disease (OSD) is an endemic disease of buffaloes in Egypt. $C$. pseudotuberculosis serotype II (biotype equi; nitrate positive) is the primary cause of OSD. The pathogenesis of these strains is related to the secretion of toxigenic factor(s) and phospholipase D (PLD) and the lipid contents of their cell walls (Selim 2001). The appearance of OSD outbreaks during the summer months was found to be related to the fact that the summer months are the breeding season for $H$. equina, the primary vector of the causative agent. The control of OSD presents several problems because there is insufficient knowledge about the epidemiology and pathogenesis of this disease (Syame et al. 2008). The role of DT in CLA, OSD and other C. pseudotuberculosis diseases in animals has not been adequately studied.
Few studies have demonstrated the isolation of the causal agent of CLA and OSD from humans worldwide. Although rare, human infections caused by C. pseudotuberculosis are frequently similar to those observed in sheep and goats (CLA); these infections usually require the excision of infected lymph nodes accompanied by supplementary antimicrobial treatment, but do not involve toxaemic manifestations. C. pseudotuberculosis is usually acquired after close contact with an infected animal and no underlying diseases or predisposing conditions have been identified in infected patients (Peel et al. 1997, Romero-Perez et al. 2004, Join-Lambert et al. 2006, Hemond et al. 2009). Only one patient with toxaemic symptoms, an injecting drug user with endocarditis, has been reported. This patient had no history of animal contact and no possible source of the C. pseudotuberculosis infection was identified (Wagner et al. 2011). Additional studies are necessary to investigate the correlation between the prevalence of C. ulcerans and C. pseudotuberculosis infections in humans and the prevalence in local cattle populations, most notably in developing countries, as previously performed for bovine tuberculosis infection in animal and human populations in Ethiopia (Shitaye et al. 2007).

There has been an increase in the incidence of disease caused by non-toxigenic $C$. diphtheriae. Non-toxigenic strains generally cause persistent sore throats and severe pharyngitis/tonsillitis and invasive diseases, such as endocarditis, septic arthritis, splenic abscesses and osteomyelitis, are not uncommon (Galazka 2000, Dzupova et al. 2005, Hirata Jr et al. 2008, Farfour et al. 2012). In non-industrialised countries there is an overall lack of information on the prevalence of colonisation by and diseases caused by non-toxigenic $C$. diphtheriae in the population due to a reduction in the frequency of routine screening for this organism. Because of non-toxigenic $C$. diphtheriae infection may not be recognised by healthcare professionals and non-toxigenic C. diphtheriae is considered an emerging pathogen of increasing significance worldwide there is an urgent need for increased clinical awareness, especially for immunocompromised patients, in whom complications can arise (Gomes et al. 2009, Edwards et al. 2011, Mattos-Guaraldi et al. 2011).

The data indicate that there is still a lack of information on the prevalence of disease caused by potentially toxigenic corynebacteria. Therefore, to better understand the mechanisms of carriage/transmission, determine the incidence rates and analyse the variation among non-toxigenic and toxigenic strains, it is imperative to use assays that can rapidly and accurately detect these three pathogens (Connor et al. 2007, Estevao et al. 2007, Kraeva et al. 2007, Baird \& Malone 2010, Komiya et al. 2010, Konrad et al. 2010, Sharpe et al. 2010). In the present study, a multiplex polymerase chain reaction (mPCR) assay was developed to identify $C$. diphtheriae, C. ulcerans and C. pseudotuberculosis and differentiate between toxigenic and non-toxigenic strains. This assay will serve as a complementary method for the timely laboratory diagnosis of infected animals and/or humans and for epidemiological studies. 


\section{MATERIALS AND METHODS}

Bacterial strains and identification procedures - This study was carried out using 213 strains of Corynebacterium and coryneform bacteria (Supplementary data). Microorganisms from international reference laboratories [the National Culture Type Collection (NCTC) (UK), the American Type Culture Collection (ATCC) (USA) and the Centers for Disease Control and Prevention (CDC) (USA)] were used as controls: non-toxigenic $C$. diphtheriae biotype mitis (ATCC 27010) and C. pseudotuberculosis (FRC41, genome sequence deposited in GenBank), toxigenic C. ulcerans (CDC KC279) and C. diphtheriae biotypes mitis (ATCC 27012 and CDC E8392), intermedius (CDC D7920) and gravis (NCTC 13129), C. jeikeium (ATCC 43734), C. minutissimum (ATCC 23348), C. striatum (CDC F378), Rhodococcus equi (ATCC 33701 and ATCC 10146), Nocardia asteroides (ATCC 7772) and Nocardia brasiliensis (ATCC 7771).

The identification of corynebacteria was based on the results of both standard biochemical tests (Efstratiou \& George 1999, Funke \& Bernard 2007) and a commercial kit: the API Coryne System (bioMérieux, LaBalme-les-Grottes, France) (Soto et al. 1994). A DNase test was also performed to differentiate $C$. diphtheriae and C. ulcerans from C. pseudotuberculosis and other Corynebacterium spp (Pimenta et al. 2008b). A reverse CAMP reaction was performed using Staphylococcus aureus ATCC 25923. A nitrate test was used to differentiate the C. pseudotuberculosis biovars equi and ovis. The conventional phenotypic tests used to identify the potentially toxigenic species are listed in Table I.

Stock cultures were maintained as suspensions in $10 \%$ skim milk containing $25 \%$ glycerol at $-20^{\circ} \mathrm{C}$. The microorganisms were cultured on Columbia agar base (CAB) (BBL, Sparks, USA) containing 5\% sheep blood for $24-48 \mathrm{~h}$ at $37^{\circ} \mathrm{C}$ for all the phenotypic and genotypic procedures described in this study. For DNA extraction, microorganisms were grown on $\mathrm{CAB}$.

Toxigenicity tests - All C. diphtheriae, C. ulcerans and $C$. pseudotuberculosis strains were evaluated for the presence of the tox gene by PCR using the DT primer set (PCR-DT), which targets fragment A of diphtheria toxin. The primer pair (forward, ATCCACTTTTAGTGCGAGAACCTTCGTCA and reverse, GAAAACTTTTCTTCGTACCACGGGACTAA) was able to amplify a 248 bp fragment from both the control and clinical strains (Pallen et al. 1994, Efstratiou et al. 1998).

$m P C R$ - The conditions for amplification using this mPCR assay were based on reactions described previously (Pacheco et al. 2007, Pimenta et al. 2008a, b). The nucleotide primers used for $\mathrm{MPCR}$ are listed in Table I. In this study, primers targeting the $16 \mathrm{~S}$ rRNA sequences (816 bp) of both C. pseudotuberculosis and C. ulcerans strains were used along with a reverse primer for the amplification of a pld sequence specific for C. pseudotuberculosis (203 bp) to discriminate C. pseudotuberculosis from C. ulcerans. In addition, a primer pair, Dipht 4 (Nakao et al. 1996), that amplifies a region linking the $\mathrm{A}$ and B fragments of the DT gene was used to generate an

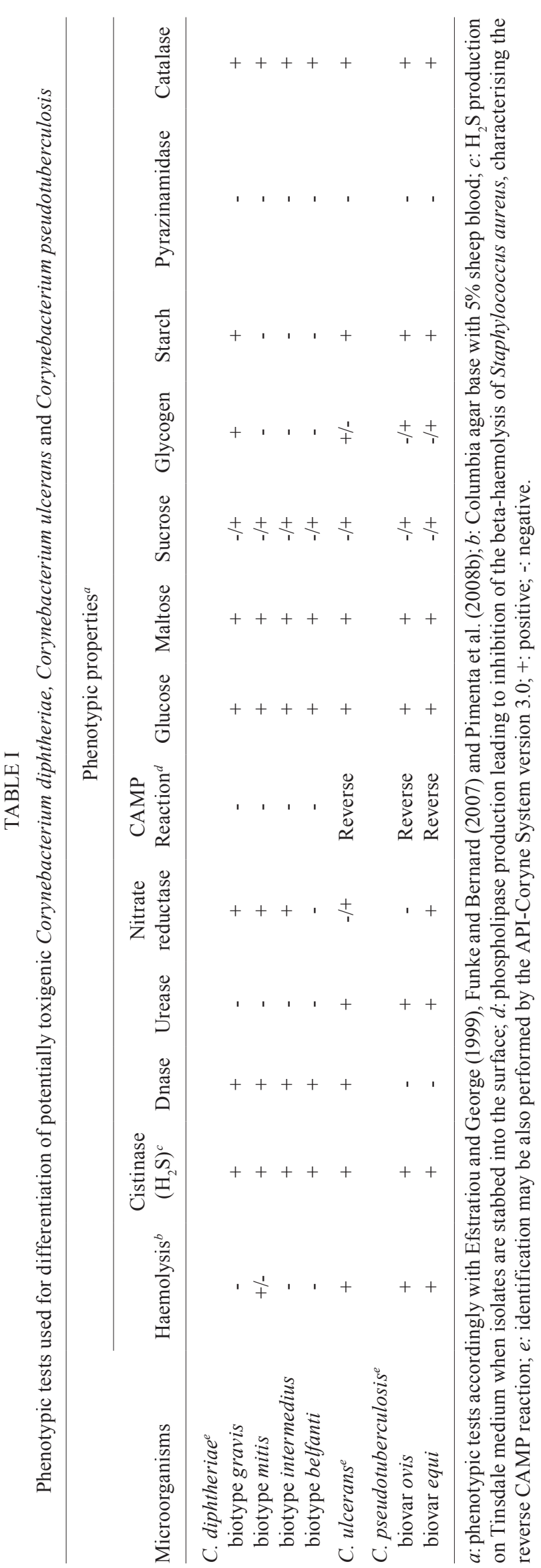


amplicon of $303 \mathrm{bp}$, which is between the size of the amplicons for $r p o B(446 \mathrm{bp})$ and $d t x R(258 \mathrm{bp})$ of $C$. diphtheriae strains. The amplification of the $r p o B$ gene was used both as an internal control and to confirm that the isolate was a Corynebacterium sp. when no other amplicons were observed after the amplification reaction.

Microbial DNA was extracted by boiling a suspension containing a loopful of freshly grown bacteria on $\mathrm{CAB}$ in $500 \mu \mathrm{L}$ of sterile deionised MilliQ water for 10 min. The suspension was centrifuged at 13,000 rpm and $1 \mu \mathrm{L}$ of the supernatant was used in the final multiplex reaction described in Table II, with primers diluted to 2 $\mathrm{mM}$. The amplification was performed in a MyCycler thermal cycler (BioRad Laboratories).

The amplified products were observed after electrophoresis on $1 \%$ agarose gels and SYBR green staining.

\section{RESULTS}

Identification of $C$. diphtheriae, C. ulcerans and C. pseudotuberculosis isolates - The microorganisms were identified by both biochemical assays and mPCR. All sucrose-fermenting and non-sucrose-fermenting $C$. diphtheriae and C. ulcerans strains exhibited DNase activity, whereas 93 of the $C$. pseudotuberculosis strains belonging to biotypes ovis and equi were negative for the expression of DNAse. The urease production assay showed positive results for C. ulcerans and C. pseudotuberculosis; both species also inhibited the beta-haemolysis of $S$. aureus ATCC 25923, indicating a positive reverse CAMP reaction.
The API profiles identified all microorganisms included in this study to the species level, with percentages greater than 98\%. Only Corynebacterium strains that were identified with API at percentages higher than $98 \%$, except for five strains belonging to the C. amycolatum complex, were used in this investigation. Using these confirmed strains and conventional biochemical tests was important for the accuracy of the MPCR assay.

The MPCR was identified all C. pseudotuberculosis strains independently of the biotype (equi or ovis), yielding at least three amplicons: $816 \mathrm{bp}$, corresponding to $16 \mathrm{~S}$ $r R N A, 446 \mathrm{bp}$, corresponding to $r p o B$, and $203 \mathrm{bp}$, corresponding to pld. C. ulcerans had only two amplicons, which corresponded to $16 S \mathrm{rRNA}$ and rpoB. The C. ulcerans strains did not produce amplicons for the pld gene, although PLD was expressed by all strains, confirming the specificity of the primer (pld R) used in this study for $C$. pseudotuberculosis. The MPCR also identified all sucrose-fermenting and non-sucrose-fermenting $C$. diphtheriae strains independently of the biotype (gravis, mitis, intermedius and belfanti) or site of colonisation (respiratory tract, skin, bone and blood), yielding amplicons for at least two genes, rpoB (446 bp) and $d t x R$ (258 bp).

In this investigation, all isolates of $C$. diphtheriae, $C$. pseudotuberculosis and C. ulcerans yielded the amplicons targeted in the mPCR assay, giving the amplification pattern presented in Figure. No isolates identified as the species above yielded unequivocally different amplification patterns using the mPCR conditions described in this study. The additional amplicon observed in DT gene-

TABLE II

Deoxyoligonucleotide primers and amplification steps for simultaneous characterization of Corynebacterium diphtheriae, Corynebacterium pseudotuberculosis and Corynebacterium ulcerans by the multiplex polymerase chain reaction used in this study

\begin{tabular}{|c|c|c|}
\hline Components $^{a}$ & $\begin{array}{l}\text { Volume } \\
\quad(\mu \mathrm{L})\end{array}$ & Amplification reaction \\
\hline Accuprime buffer (Invitrogen) & 1.0 & \\
\hline 16SF-ACCGCACTTTAGTGTGTGTG & 0.3 & \\
\hline 16SR-TCTCTACGCCGATCTTGTAT & 0.3 & \\
\hline C2700 F (rpos) CGTATGAACATCGGCCAGGT & 0.2 & \\
\hline C3130 R (rpoв) TCCATTTCGCCGAAGCGCTG & 0.2 & 1: initial denaturation $\left(95^{\circ} \mathrm{C}-3 \mathrm{~min}\right)$ \\
\hline pld F-ATAAGCGTAAGCAGGGAGCA & 0.2 & \\
\hline pld R-ATCAGCGGTGATTGTCTTCC & 0.2 & 2: 35 cycles $\left(95^{\circ} \mathrm{C}-1 \mathrm{~min}, 55^{\circ} \mathrm{C}-40 \mathrm{~s}, 68^{\circ} \mathrm{C}-1 \mathrm{~min}: 30 \mathrm{~s}\right)$ \\
\hline$d t x R$ 1F-GGGACTACAACGCAACAAGAA & 0.2 & \\
\hline$d t x R$ 1R-CAACGGTTTGGCTAACTGTA & 0.2 & 3: final extension $\left(68^{\circ} \mathrm{C}-5 \mathrm{~min}\right)$ \\
\hline dipht 4F-GAACAGGCGAAAGCGTTAAGC & 0.2 & \\
\hline dipht 4R-TGCCGTTTGATGAAATTCTTC & 0.2 & \\
\hline Accuprime Taq polimerase & 0.5 & \\
\hline $\mathrm{H}_{2} \mathrm{O}$ milliQ deionized & 5.3 & \\
\hline DNA extracted & 1.0 & \\
\hline Total volume & 10 & \\
\hline
\end{tabular}

$a$ : AccuPrime buffer (Invitrogen Co) contains all components necessary for optimal amplification reactions. Primers were used in concentration of $2 \mathrm{mM}$. 
bearing strains (dipht 4- 303 bp) was correlated with amplification by the DT primer set (PCR-DT), which targets fragment A of DT (248 bp). The primers targeting fragment A of DT gave a product with a molecular mass similar to the $d t x R$ amplicon (258 bp) and therefore, these primers not included in this MPCR assay.

All tested Corynebacterium spp that were not associated with C. diphtheriae, C. pseudotuberculosis or C. ulcerans, except for Corynebacterium pseudodiphtheriticum strains, only yielded amplicons for rров. The rроB sequence of $C$. pseudodiphtheriticum could only be amplified using the cycling conditions described in this study after replacing C3130 R (rpoB) TCCATTTCGCCGAAGCGCTG with the reverse primer 5'-TCCATCTCACCGAAGCGCTC-3'.

The Gram-positive bacteria Nocardia sp, R. equi and Oerskovia sp. included in this investigation did not yield amplicons in this mPCR assay using the cycling conditions described.

\section{DISCUSSION}

The prevalence of $C$. diphtheriae, C. ulcerans and C. pseudotuberculosis infections is greater than previously recognised by the medical and veterinary communities in many regions worldwide due to the difficulty in accurately identifying these pathogens and their ability to produce DT.

The laboratory identification of Corynebacterium organisms is usually complex and expensive, requiring the use of conventional and/or miniaturised biochemical methods (Funke \& Bernard 2007). The molecular typing methods used for the characterisation of $C$. diphtheriae, C. ulcerans and C. pseudotuberculosis are important tools for the rapid detection and identification of bacterial clones that harbour the tox gene and these methods have several advantages over the traditional methods used to determine the toxigenicity of corynebacterial isolates (Hauser et al. 1993, Pallen et al. 1994, Nakao \& Popovic 1997, Cetinkaya et al. 2002, Mothershed et al. 2002, Sing et al. 2003, Spier et al. 2004, Pacheco et al. 2007, Pimenta et al. 2008a, b).

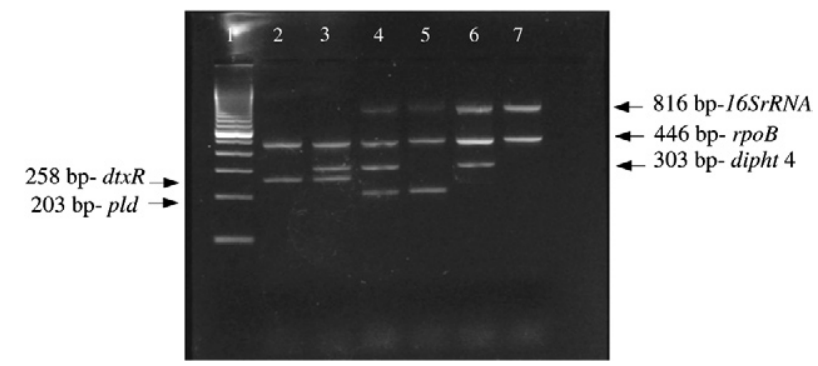

Amplification profile by multiplex polymerase chain reaction of Corynebacterium diphtheriae, Corynebacterium pseudotuberculosis and Corynebacterium ulcerans: Lane 1: molecular weight (100-bp DNA ladder); 2: C. diphtheriae ATCC 27010 (tox); 3: C. diphtheriae ATCC 27012 (tox ${ }^{+}$); 4: C. pseudotuberculosis biovar equi E31(tox ${ }^{+}$); 5: C. pseudotuberculosis biovar ovis E40 (tox); 6: C. ulcerans CDC KC279 (tox ${ }^{+}$); 7: C. ulcerans BR-AD22 (tox ); +: positive; -: negative.
In this study, a species-specific mPCR assay for the identification of potentially toxigenic human and animal isolates of C. diphtheriae, C. ulcerans and C. pseudotuberculosis was developed. The taxonomic position of most of the isolates could also be determined using this $\mathrm{mPCR}$ assay, which includes an rpoB-targeting genusspecific primer pair for the identification of Corynebacterium sp. (Khamis et al. 2004). All Corynebacterium strains used in this study, except for C. pseudodiphtheriticum isolates, yielded amplicons with the rpoB primers, as previously observed (Pacheco et al. 2007).

The MPCR method using primers for the detection of the $d t x R$ gene was also able to identify $C$. diphtheriae isolates independent of DT production, including isolates of the biotypes gravis, mitis, intermedius and belfanti, as previously demonstrated (Pimenta et al. 2008a).

C. ulcerans and C. pseudotuberculosis yielded amplicons with the $16 S$ rRNA primers, whereas only $C$. pseudotuberculosis, regardless of the biovar (ovis or equi), yielded amplicons for $p l d$, as previously described (Pacheco et al. 2007). No diverse amplicons were observed for $C$. diphtheriae after amplification with primers targeting $16 S$ rRNA or pld.

To detect toxin production by the three species included in this study, primers targeting Dipht 4 (Nakao et al. 1996), a sequence between the A and B fragments of DT, were chosen due to the adaptation of the primer sequences to the cycling conditions used for MPCR and the molecular mass of the generated amplicon, which allowed for an easier interpretation of the $\mathrm{mPCR}$ results after electrophoresis with agarose gels.

The mPCR assay yielded reliable results when performed by at least two different technicians who used the same strains at different times. For clinical purposes, C. pseudotuberculosis, C. ulcerans and toxigenic and non-toxigenic $C$. diphtheriae control strains should be included in the assay. The inclusion of these strains was shown to be essential to monitor the amplification profiles of the isolates. No non-specific amplicons were observed for other Corynebacterium spp with MPCR in this study. Amplicons were not observed for the coryneform strains tested.

The advantages of this mPCR assay over conventional biochemical procedures are its rapidity, ease of performance, the large number of strains that can be simultaneously tested and the easy interpretation of the MPCR results. This novel species-specific mPCR system may facilitate routine laboratory diagnosis and/or epidemiological research on this group of potentially zoonotic and toxigenic corynebacterial pathogens: C. pseudotuberculosis, C. ulcerans and C. diphtheriae.

\section{REFERENCES}

Aaron L, Heurtebise F, Bachelier MN, Guimard Y 2006. Pseudomembranous diphtheria caused by Corynebacterium ulcerans. Rev Med Interne 27: 333-335.

Baird GJ, Fontaine MC 2007. Corynebacterium pseudotuberculosis and its role in ovine caseous lymphadenitis. J Comp Pathol 137: $179-210$.

Baird GJ, Malone FE 2010. Control of caseous lymphadenitis in six sheep flocks using clinical examination and regular ELISA testing. Vet Rec 166: 358-362. 
Bonmarin I, Guiso N, Le Flèche-Matéos A, Patey O, Patrick AD, Levy-Bruhl D 2009. Diphtheria: a zoonotic disease in France? Vaccine 27: 4196-4200.

Braverman Y, Chizov-Ginzburg A, Saran A, Winkler M 1999. The role of houseflies (Musca domestica) in harbouring Corynebacterium pseudotuberculosis in dairy herds in Israel. Rev Sci Tech 18: 681-690.

CDC - Center for Disease Control and Prevention 2000. Three cases of toxigenic Corynebacterium ulcerans infection. Commun Dis Rep CDR Wkly 10: 49-52.

Cetinkaya B, Karahan M, Atil E, Kalin R, De Baere T, Vaneechoutte M 2002. Identification of Corynebacterium pseudotuberculosis isolates from sheep and goats by PCR. Vet Microbiol 88: 75-83.

Connor KM, Fontaine MC, Rudge K, Baird GJ, Donachie W 2007. Molecular genotyping of multinational ovine and caprine Corynebacterium pseudotuberculosis isolates using pulsed-field gel electrophoresis. Vet Res 38: 613-623.

De Zoysa A, Hawkey PM, Engler K, George R, Mann G, Reilly W, Taylor D, Efstratiou A 2005. Characterization of toxigenic Corynebacterium ulcerans strains isolated from humans and domestic cats in the United Kingdom. J Clin Microbiol 43: 4377-4381.

DeWinter LM, Bernard KA, Romney MG 2005. Human clinical isolates of Corynebacterium diphtheriae and Corynebacterium ulcerans collected in Canada from 1999 to 2003 but not fitting reporting criteria for cases of diphtheria. J Clin Microbiol 43: $3447-3449$.

Dias AA, Santos LS, Sabbadini PS, Santos CS, Silva Junior FC, Napoleão F, Nagao PE, Villas-Bôas MH, Hirata Jr R, Guaraldi AL 2011. Corynebacterium ulcerans diphtheria: an emerging zoonosis in Brazil and worldwide. Rev Saude Publica 45: 1176-1191.

Dias AA, Silva Jr FC, Pereira GA, Souza MC, Camello TC, Damasceno JA, Pacheco LG, Miyoshi A, Azevedo VA, Hirata Jr R, Bôas MH, Mattos-Guaraldi AL 2010. Corynebacterium ulcerans isolated from an asymptomatic dog kept in an animal shelter in the metropolitan area of Rio de Janeiro, Brazil. Vector Borne Zoonotic Dis 10: 743-748.

Dorella FA, Pacheco LG, Oliveira SC, Miyoshi A, Azevedo VA 2006. Corynebacterium pseudotuberculosis: microbiology, biochemical properties, pathogenesis and molecular studies of virulence. Vet Res 37: 201-218.

Dzupova O, Benes J, Kriz B, Horova B, Olexova A 2005. An unusual course of invasive infection due to non-toxigenic strain of Corynebacterium diphtheriae. Klin Mikrobiol Infekc Lek 11: 222-225.

Edwards B, Hunt AC, Hoskisson PA 2011. Recent cases of non-toxigenic Corynebacterium diphtheriae in Scotland: justification for continued surveillance. J Med Microbiol 60: 561-562.

Efstratiou A, Engler KH, Dawes CS, Sesardic D 1998. Comparison of phenotypic and genotypic methods for detection of diphtheria toxin among isolates of pathogenic corynebacteria. J Clin Microbiol 36: 3173-3177.

Efstratiou A, George RC 1999. Laboratory guidelines for the diagnosis of infections caused by Corynebacterium diphtheriae and Corynebacterium ulcerans. Commun Dis Public Health 2: 251-257.

Estevao BS, Gallardo A, Abalos A, Diaz Y, Alvarez L, Callejo R, Prieto M, Jodor N, Jensen O 2007. Diagnosis of caseous lymphadenitis in sheep from Patagonia. Rev Argent Microbiol 39: 44-46.

Farfour E, Badell E, Zasada A, Hotzel H, Tomaso H, Guillot S, Guiso N 2012. Characterization and comparison of invasive Corynebacterium diphtheriae isolates from France and Poland. $J$ Clin Microbiol 50: 173-175.
Foley JE, Spier SJ, Mihalyi J, Drazenovich N, Leutenegger CM 2004. Molecular epidemiologic features of Corynebacterium pseudotuberculosis isolated from horses. Am J Vet Res 65: 1734-1737.

Funke G, Bernard KA 2007. Coryneform Gram-positive rods. In PR Murray, EJ Baron, JA Jorgensen, ML Landry, MA Pfaller (eds.), Manual of clinical microbiology, American Society for Microbiology Press, Washington DC, p. 485-514.

Galazka AM 2000. The changing epidemiology of diphtheria in the vaccine era. J Infect Dis 181 (Suppl.): S2-S9.

Gomes DL, Martins CA, Faria LM, Santos LS, Santos CS, Sabbadini PS, Souza MC, Alves GB, Rosa AC, Nagao PE, Pereira GA, Hirata Jr R, Mattos-Guaraldi AL 2009. Corynebacterium diphtheriae as an emerging pathogen in nephrostomy catheter-related infection: evaluation of traits associated with bacterial virulence. J Med Microbiol 58: 1419-1427.

Hadfield TL, Mcevoy P, Polotsky Y, Tzinserling VA, Yakovlev AA 2000. The pathology of diphtheria. J Infect Dis 181: 116-120.

Hall AJ, Cassiday PK, Bernard KA, Bolt F, Steigerwalt AG, Bixler D, Pawloski LC, Whitney AM, Iwaki M, Baldwin A, Dowson CG, Komiya T, Takahashi M, Hinrikson HP, Tondella ML 2010. Novel Corynebacterium diphtheriae in domestic cats. Emerg Infect Dis 16: 688-691.

Hauser D, Popoff MR, Kiredjian M, Boquet P, Bimet F 1993. Polymerase chain reaction assay for diagnosis of potentially toxigenic Corynebacterium diphtheriae strains: correlation with ADP-ribosylation activity assay. J Clin Microbiol 31: 2720-2723.

Hemond V, Rosenstingl S, Auriault ML, Galanti MJ, Gatfosse M 2009. Axillary lymphadenitis due to Corynebacterium pseudotuberculosis in a 63-year-old patient. Med Mal Infect 39: 136-139.

Hirata Jr R, Pereira GA, Filardy AA, Gomes DL, Damasco PV, Rosa AC, Nagao PE, Pimenta FP, Mattos-Guaraldi AL 2008. Potential pathogenic role of aggregative-adhering Corynebacterium diphtheriae of different clonal groups in endocarditis. Braz J Med Biol Res 41: 986-991.

Hogg RA, Wessels J, Hart J, Efstratiou A, De Zoysa A, Mann G, Allen T, Pritchard GC 2009. Possible zoonotic transmission of toxigenic Corynebacterium ulcerans from companion animals in a human case of fatal diphtheria. Vet Rec 165: 691-692.

Join-Lambert OF, Ouache M, Canioni D, Beretti JL, Blanche S, Berche P, Kayal S 2006. Corynebacterium pseudotuberculosis necrotizing lymphadenitis in a twelve-year-old patient. Pediatr Infect Dis $J$ 25: 848-851.

Katsukawa C, Kawahara R, Inoue K, Ishii A, Yamagishi H, Kida K, Nishino S, Nagahama S, Komiya T, Iwaki M, Takahashi M 2009. Toxigenic Corynebacterium ulcerans isolated from the domestic dog for the first time in Japan. Jpn J Infect Dis 62: 171-172.

Katsukawa C, Komiya T, Yamagishi H, Ishii A, Nishino S, Nagahama S, Iwaki M, Yamamoto A, Takahashi M 2012. Prevalence of Corynebacterium ulcerans in dogs in Osaka, Japan. J Med Microbiol 61: 266-273.

Khamis A, Raoult D, La Scola B 2004. rpoB gene sequencing for identification of Corynebacterium species. J Clin Microbiol 42: 3925-3931.

Komala TS, Ramlan M, Yeoh NN, Surayani AR, Sharifah Hamidah SM 2008. A survey of caseous lymphadenitis in small ruminant farms from two districts in Perak, Malaysia - Kinta and Hilir Perak. Trop Biomed 25: 196-201.

Kombarova S, Kim C, Melnikov V, Reeves M, Borisova O, Mazurova I, Popovic T 2001. Rapid identification of Corynebacterium diphtheriae clonal group associated with diphtheria epidemic, Russian Federation. Emerg Infect Dis 7: 133-136. 
Komiya T, Seto Y, De Zoysa A, Iwaki M, Hatanaka A, Tsunoda A, Arakawa Y, Kozaki S, Takahashi M 2010. Two Japanese Corynebacterium ulcerans isolates from the same hospital: ribotype, toxigenicity and serum antitoxin titre. J Med Microbiol 59: 1497-1504.

Konrad R, Berger A, Huber I, Boschert V, Hormansdorfer S, Busch U, Hogardt M, Schubert S, Sing A 2010. Matrix-assisted laser desorption/ionisation time-of-flight (MALDI-TOF) mass spectrometry as a tool for rapid diagnosis of potentially toxigenic Corynebacterium species in the laboratory management of diphtheria-associated bacteria. Euro Surveill 15: pii: 19702.

Kraeva LA, Manina Z, Tseneva GI, Radchenko AG 2007. Etiologic role of Corynebacterium non diphtheriae in patients with different pathology. Zh Mikrobiol Epidemiol Immunobiol 5: 3-7.

Lartigue MF, Monnet X, Le Fleche A, Grimont PA, Benet JJ, Durrbach A, Fabre M, Nordmann P 2005. Corynebacterium ulcerans in an immunocompromised patient with diphtheria and her dog. J Clin Microbiol 43: 999-1001.

Leggett BA, De Zoyza A, Abbott YE, Leonard N, Markey B, Efstratiou A 2010. Toxigenic Corynebacterium diphtheriae isolated from a wound in a horse. Vet Rec 166: 656-657.

Mattos-Guaraldi AL, Hirata Jr R, Damasco PV 2011. Difteria no Brasil e no mundo: aspectos sobre o cenário atual. Rev Imun SBIM (Suppl. 1): S2-S26.

Mattos-Guaraldi AL, Moreira LO, Damasco PV, Hirata Jr R 2003. Diphtheria remains a threat to health in the developing world - an overview. Mem Inst Oswaldo Cruz 98: 987-993.

Mattos-Guaraldi AL, Sampaio JLM, Santos CS, Pimenta FP, Pereira GA, Pacheco LGC, Miyoshi A, Azevedo V, Moreira LO, Gutierrez FL, Costa JLF, Costa-Filho R, Damasco PV, Camello TCF, Hirata Jr R 2008. First detection of Corynebacterium ulcerans producing a diphtheria-like toxin in a case of human with pulmonary infection in the Rio de Janeiro metropolitan area, Brazil. Mem Inst Oswaldo Cruz 103: 396-400.

Mothershed EA, Cassiday PK, Pierson K, Mayer LW, Popovic T 2002. Development of a real-time fluorescence PCR assay for rapid detection of the diphtheria toxin gene. J Clin Microbiol 40: 4713-4719.

Nakao H, Popovic T 1997. Development of a direct PCR assay for detection of the diphtheria toxin gene. J Clin Microbiol 35: 1651-1655.

Nakao H, Pruckler JM, Mazurova IK, Narvskaia OV, Glushkevich T, Marijevski VF, Kravetz AN, Fields BS, Wachsmuth IK, Popovic T 1996. Heterogeneity of diphtheria toxin gene, tox, and its regulatory element, $d t x R$, in Corynebacterium diphtheriae strains causing epidemic diphtheria in Russia and the Ukraine. J Clin Microbiol 34: 1711-1716.

Pacheco LG, Pena RR, Castro TL, Dorella FA, Bahia RC, Carminati R, Frota MN, Oliveira SC, Meyer R, Alves FS, Miyoshi A, Azevedo V 2007. Multiplex PCR assay for identification of Corynebacterium pseudotuberculosis from pure cultures and for rapid detection of this pathogen in clinical samples. J Med Microbiol 56: 480-486.

Pallen MJ, Hay AJ, Puckey LH, Efstratiou A 1994. Polymerase chain reaction for screening clinical isolates of corynebacteria for the production of diphtheria toxin. J Clin Pathol 47: 353-356.

Pappenheimer AM 1993. The story of a toxic protein, 1888-1992. Protein Sci 2: 292-298.

Peel MM, Palmer GG, Stacpoole AM, Kerr TG 1997. Human lymphadenitis due to Corynebacterium pseudotuberculosis: report of ten cases from Australia and review. Clin Infect Dis 24: 185-191.

Perkins SL, Magdesian KG, Thomas WP, Spier SJ 2004. Pericarditis and pleuritis caused by Corynebacterium pseudotuberculosis in a horse. J Am Vet Med Assoc 224: 1133-1138.
Pimenta FP, Hirata Jr R, Rosa AC, Milagres LG, Mattos-Guaraldi AL 2008a. A multiplex PCR assay for simultaneous detection of Corynebacterium diphtheriae and differentiation between nontoxigenic and toxigenic isolates. J Med Microbiol 57: 1438-1439.

Pimenta FP, Souza MC, Pereira GA, Hirata Jr R, Camello TC, Mattos-Guaraldi AL 2008b. DNase test as a novel approach for the routine screening of Corynebacterium diphtheriae. Lett Appl Microbiol 46: 307-311.

Pratt SM, Spier SJ, Carroll SP, Vaughan B, Whitcomb MB, Wilson WD 2005. Evaluation of clinical characteristics, diagnostic test results and outcome in horses with internal infection caused by Corynebacterium pseudotuberculosis: 30 cases (1995-2003). J Am Vet Med Assoc 227: 441-448.

Romero-Perez JC, Suner-Machado M, Batista-Diaz N 2004. Corynebacterium pseudotuberculosis lymphadenitis in a young patient. Rev Clin Esp 204: 388-389.

Saikya L, Nath R, Saikya NJ, Choudhury G, Sarkar M 2010. A diphtheria outbreak in Assam, India. Southeast Asian J Trop Med Public Health 41: 647-652.

Schuhegger R, Schoerner C, Dlugaiczyk J, Lichtenfeld I, Trouillier A, Zeller-Peronnet V, Busch U, Berger A, Kugler R, Hormansdorfer S, Sing A 2009. Pigs as source for toxigenic Corynebacterium ulcerans. Emerg Infect Dis 15: 1314-1315.

Selim SA 2001. Oedematous skin disease of buffalo in Egypt. $J$ Vet Med B Infect Dis Vet Public Health 48: 241-258.

Seto Y, Komiya T, Iwaki M, Kohda T, Mukamoto M, Takahashi M, Kozaki S 2008. Properties of corynephage attachment site and molecular epidemiology of Corynebacterium ulcerans isolated from humans and animals in Japan. Jpn J Infect Dis 61: 116-122.

Seyffert N, Guimaraes AS, Pacheco LG, Portela RW, Bastos BL, Dorella FA, Heinemann MB, Lage AP, Gouveia AM, Meyer R, Miyoshi A, Azevedo V 2010. High seroprevalence of caseous lymphadenitis in Brazilian goat herds revealed by Corynebacterium pseudotuberculosis secreted proteins-based ELISA. Res Vet Sci 88: 50-55.

Sharpe AE, Brady CP, Johnson AJ, Byrne W, Kenny K, Costello E 2010. Concurrent outbreak of tuberculosis and caseous lymphadenitis in a goat herd. Vet Rec 166: 591-592.

Shitaye JE, Tsegaye W, Pavlik I 2007. Bovine tuberculosis infection in animal and human populations in Ethiopia: a review. Vet Med 52: $317-332$.

Sing A, Hogardt M, Bierschenk S, Heesemann J 2003. Detection of differences in the nucleotide and amino acid sequences of diphtheria toxin from Corynebacterium diphtheriae and Corynebacterium ulcerans causing extrapharyngeal infections. J Clin Microbiol 41: 4848-4851.

Soto A, Zapardiel J, Soriano FF 1994. Evaluation of API Coryne system for identifying coryneform bacteria. J Clin Pathol 47: 756-759.

Spier SJ, Leutenegger CM, Carroll SP, Loye JE, Pusterla JB, Carpenter TE, Mihalyi JE, Madigan JE 2004. Use of a real-time polymerase chain reaction-based fluorogenic 5' nuclease assay to evaluate insect vectors of Corynebacterium pseudotuberculosis infections in horses. Am J Vet Res 65: 829-834.

Stefanska I, Rzewuska M, Binek M 2008. Evaluation of three methods for DNA fingerprinting of Corynebacterium pseudotuberculosis strains isolated from goats in Poland. Pol J Microbiol 57: 105-112.

Syame SM, EL-Hewairy HM, Selim SA 2008. Protection of buffaloes against oedematous skin disease by recombinent-bacterin and toxoid-bacterin vaccines. Global Vet 2:151-156. 
Sykes JE, Mapes S, Lindsay LL, Samitz E, Byrne BA 2010. Corynebacterium ulcerans bronchopneumonia in a dog. J Vet Intern Med 24: 973-976.

Tarello W, Theneyan M 2008. Corynebacterium pseudotuberculosis and Corynebacterium renale isolated from two Arabian oryx (Oryx leucoryx). Vet Rec 162: 862-863.

Taylor DJ, Efstratiou A, Reilly WJ 2002. Diphtheria toxin production by Corynebacterium ulcerans from cats. Vet Rec 150: 355.

Tejedor-Junco MT, Lupiola P, Schulz U, Gutierrez C 2008. Isolation of nitrate-reductase positive Corynebacterium pseudotuberculosis from dromedary camels. Trop Anim Health Prod 41: 711-714.

Von Hunolstein C, Alfarone G, Scopetti F, Pataracchia M, La Valle R, Franchi F, Pacciani L, Manera A, Giammanco A, Farinelli S, Engler K, De Zoysa A, Efstratiou A 2003. Molecular epidemiology and characteristics of Corynebacterium diphtheriae and Coryne- bacterium ulcerans strains isolated in Italy during the 1990s. J Med Microbiol 52: 181-188.

Wagner KS, White JM, Neal S, Crowcroft NS, Kupreviciene N, Paberza R, Lucenko I, Joks U, Akbas E, Alexandrou-Athanassoulis H, Detcheva A, Vuopio J, von Hunolstein C, Murphy PG, Andrews N, Efstratiou A 2011. Screening for Corynebacterium diphtheriae and Corynebacterium ulcerans in patients with upper respiratory tract infections 2007-2008: a multicentre European study. Clin Microbiol Infect 17: 519-525.

Wong TP, Groman N 1984. Production of diphtheria toxin by selected isolates of Corynebacterium ulcerans and Corynebacterium pseudotuberculosis. Infect Immun 43: 1114-1116.

Yeruham I, Braverman Y, Shpigel NY, Chizov-Ginzburg A, Saran A, Winkler M 1996. Mastitis in dairy cattle caused by Corynebacterium pseudotuberculosis and the feasibility of transmission by houseflies. Vet Q 18: 87-89. 
Number of strains of Corynebacterium species and coryneform bacteria used in this study

\begin{tabular}{|c|c|c|c|}
\hline Microorganisms & Number of strains & Source & Country \\
\hline $\begin{array}{l}\text { Corynebacterium diphtheriae } \\
\text { (biotypes gravis, mitis, intermedius and belfanti) }\end{array}$ & $18\left(10\right.$ tox $^{+}$and 8 tox $)$ & Human & Brazil \\
\hline Corynebacterium ulcerans & $7\left(2\right.$ tox $^{+}$and 5 tox $)$ & Human and animal & Brazil \\
\hline $\begin{array}{l}\text { Corynebacterium pseudotuberculosis } \\
\text { (biovars ovis and equi }{ }^{a} \text { ) }\end{array}$ & $93\left(20\right.$ tox $^{+a}$ and 73 tox $)$ & Animal & Egypt and/or Brazil \\
\hline Corynebacterium pseudodiphtheriticum & 7 & Human & Brazil \\
\hline Corynebacterium jeikeium & 1 & Human & Brazil \\
\hline Corynebacterium afermentans & 2 & Human & Brazil \\
\hline Corynebacterium minutissimum & 5 & Human & Brazil \\
\hline Corynebacterium propinquum & 4 & Human & Brazil \\
\hline Corynebacterium amycolatum & 9 & Human & Brazil \\
\hline Corynebacterium striatum & 4 & Human & Brazil \\
\hline Corynebacterium xerosis & 3 & Human & Brazil \\
\hline Corynebacterium amycolatum/xerosis/minutissimum complex & 5 & Human & Brazil \\
\hline Nocardia sp. & 4 & Human & Brazil \\
\hline Oerskovia sp. & 2 & Human & Brazil \\
\hline Rhodococcus equi & 27 & Human and animal & Brazil \\
\hline
\end{tabular}

a: all C. pseudotuberculosis biovar equi strains were toxigenic (tox ${ }^{+}$); tox: non-toxigenic. 